\title{
Differential memory and executive functions in demented patients with Parkinson's and Alzheimer's disease
}

\author{
Irene Litvan, Erich Mohr, Jill Williams, Claudia Gomez, Thomas N Chase
}

\begin{abstract}
Selected aspects of verbal memory and executive function were compared in 11 demented Parkinson's disease (PD) patients and 11 Alzheimer's disease (AD) patients with equally severe dementia, with 11 healthy controls matched for age and education. Semantic and episodic memory were impared in all patients compared with controls, but to a relatively greater degree in AD patients than in those with PD. In contrast, demented PD patients were relatively more compromised on executive tasks. These findings, taken in the context of the neuropathological and neurochemical overlap between demented PD and $A D$ patients, suggest that differences in neurobehavioural patterns in patients with these diseases are relative, rather than absolute.
\end{abstract}

It is estimated that about one in five patients with Parkinson's disease (PD) will become demented. ${ }^{1}$ Despite widespread agreement on PD's association with cognitive deficits, ${ }^{2}$ the characterisation of these decrements and their similarity to those observed in the dementia of Alzheimer's disease (AD) remains controversial. $^{3-10}$ Many aspects of Parkinsonian dementia (neuropathological, neurochemical, neurobehavioural) have been associated with AD. ${ }^{811-13}$ Conversely, possible differences between groups have also been stressed. ${ }^{5101415}$

Loss of executive function is generally regarded as a central component of the intellectual deficit in PD; its decline has been described in demented as well as in nondemented PD patients, even in the early stages of the disease. ${ }^{514-16}$ In contrast, executive dysfunction in Alzheimer's disease patients is usually milder and begins later in the course of the illness. ${ }^{15}$ Loss in memory function on the other hand, is a major feature of Alzheimer's disease. It is generally viewed as a central and early feature in $\mathrm{AD}$ patients in whom impairment of both episodic and semantic memory has been described. ${ }^{17} 18$ Memory impairment has also been reported in PD patients, but has been attributed by some researchers to frontal lobe dysfunction. ${ }^{14}$ Deficits in episodic memory, notably contextbound knowledge $^{19}$ frequently occurs in PD demented and non-demented patients. ${ }^{20-24}$ Abnormalities in semantic memory (retrieval of learned knowledge that is context-free) in PD patients is less certain. ${ }^{20-25}$
Previous studies generally did not match Parkinson's and Alzheimer's patients for global dementia severity making direct comparisons in cognitive performance difficult. ${ }^{10}$ In an attempt to clarify possible differences between dementia types, we compared demented $\mathrm{PD}$ and $\mathrm{AD}$ patients on tests of executive function and memory which are prominent in the description of their neurobehavioural deficits. To insure comparable levels of overall cognitive impairment, both patient groups were matched for degree of dementia (Mattis Dementia Rating Scale), ${ }^{26}$ as well as age and education.

\section{Subjects and methods}

Eleven patients ( 10 men and one woman) with idiopathic PD and dementia (DSM-III-R criteria $^{27}$ ) were compared with 11 patients (five men and six women) with AD (NINCDS-ADRDA criteria $^{28}$ and DSM-III-R criteria) matched for severity [Total Mattis Dementia Rating Scale score: mean (SEM) 125 (2) and 122 (2) respectively], and with 11 healthy control subjects [six men and five women, Total Mattis Dementia Rating Scale score: $143(0.5)]$. Entry criteria for PD patients included at least two of the following typical signs: tremor, rigidity or bradykinesia. No patients with atypical signs (that is, supranuclear ophthalmoparesis, long tract or cerebellar dysfunction) were included. In all subjects, the diagnosis of PD had always preceded the development of dementia. Admission criteria were set arbitrarily to a Total Mattis Dementia Rating Scale score between 136 and 110 to allow for inclusion of mildly to moderately impaired individuals. No patient had a history of alcoholism, other neurological disorders or stereotaxic surgery. Subjects were matched for age [66 (2) years, controls; 66 (3), AD; $69(1), \quad \mathrm{PD}]$ and educational level $[17(1)$ years, controls; 18 (5), AD; 16 (2), PD]. Mean duration of symptoms was 13 (1) years for PD patients and $5(1)$ years for $\mathrm{AD}$ patients $(\mathrm{p}<0.001)$. AD patients' mean score on the Hachinski Scale was 1 . PD patients had a mean score of $3(0 \cdot 1)$ on the Hoehn and Yahr Scale and 17 (2) on the modified Columbia Scale ${ }^{29}$ while treated. There was no clinical evidence of a motor deficit in the AD patients or controls. Ten PD patients were receiving optimal doses of one or more anti-Parkinsonian medications in the following daily doses: levodopa-carbidopa 645 (100) $\mathrm{mg}$ (range, 200-1200 mg) in 10 patients; bromocriptine $21(7 \cdot 5) \mathrm{mg}(2 \cdot 5-40$ 
$\mathrm{mg}$ ) in four patients; amantadine $200 \mathrm{mg}$ in two patients; trihexyphenidyl hydrochloride 4 $\mathrm{mg}$ in one patient; and lisuride $3.8 \mathrm{mg}$ in one patient. None of the AD patients were treated with centrally active drugs at the time of neuropsychological testing. Informed consent was obtained from all subjects. The same set of patients also participated in a study of visuospatial function which will be reported separately. ${ }^{30}$

The following neuropsychological tests were employed to assess intellectual, memory and executive functions: Global memory function was assessed with the memory quotient of the Wechsler Memory Scale (WMS) $)^{31}$ and the memory subtest of the MDRS. Episodic memory was measured with a modified version of the Rey-Auditory Verbal Learning Test (RAVLT), ${ }^{32}$ in which a list of eight words was presented five times with free recall immediately after each trial, followed by a delayed recall and recognition condition, and with immediate recall of the WMS stories and the paired-associates subtest of the WMS. Semantic memory was evaluated in the FAS Fluency Test $^{33}$ (test of verbal phonological fluency requiring the production of words beginning with the letters $\mathrm{F}, \mathrm{A}$, and $\mathrm{S}$ for one minute each), the Supermarket Fluency Test $^{26}$ (test of verbal semantic fluency requiring the naming of items normally found in a supermarket, for one minute), and the information and vocabulary subtests of the WAIS-R. ${ }^{34}$ Word-finding ability was evaluated by the Boston Naming Test. ${ }^{35}$ Short term memory span was evaluated by the digit span of the WAIS-R, attention by the attention subtest of the MDRS. Executive function measures consisted of the conceptualisation subtest of the MDRS and the Wisconsin Card
Sorting Test (WCST). ${ }^{36}$ Depression was assessed by the Hamilton and Beck Depression Scales. ${ }^{37} 38$

Data were analysed by Analysis of Variance procedures $^{39}$ and, where appropriate, with Pearson correlational measures. ${ }^{40}$

\section{Results}

In comparison with control subjects, patients with $P D$ and $A D$ had significant deficits on the full-scale IQ, verbal IQ, and performance IQ (WAIS-R) (table). Although the two patient groups were selected on the basis of being equivalent in global intellectual deterioration, there were significant differences in their performance on the memory and concept formation subtests of the Mattis Dementia Rating Scale (MDRS): patients with PD were more impaired on concept formation items relative to patients with $A D$, while the performance of the $\mathrm{AD}$ patients was poorer on memory items relative to patients with PD (table). All other subtest scores were similar.

Attention testing showed that both patient groups had poorer performance than control subjects $(p<0.001)$ on the attention subtest of the MDRS and on the digit span of the WAIS-R, but no differences were found between groups (table).

The memory quotient of the WMS revealed profound deficits in both patient groups compared with controls (32\% decline in PD and $45 \%$ in $\mathrm{AD})$. Patients with $\mathrm{AD}$ were significantly more impaired that $\mathrm{PD}$ patients (table).

Episodic memory was abnormal in both patient groups, compared with control subjects. Deficits in the Rey Auditory Verbal

Table Neuropsychological performance of healthy controls and demented patients with Alzheimer's (AD) and Parkinson's disease (PD)

\begin{tabular}{|c|c|c|c|c|}
\hline & Controls $(n=11)$ & \multicolumn{2}{|c|}{$A D(n=11) P D(n=11)$} & \\
\hline $\begin{array}{l}\text { Mattis Dementia Rating Scale } \\
\text { Total Score } \\
\text { Attention } \\
\text { Initiation and perseveration } \\
\text { Memory } \\
\text { Construction } \\
\text { Conceptualisation }\end{array}$ & $\begin{array}{l}143(0 \cdot 5) a^{\star \star \star \star}, b^{\star \star \star \star} \\
37(0 \cdot 1) a^{\star \star}, b^{\star \star \star} \\
37(0 \cdot 2) a^{\star \star}, b^{\star \star} \\
25(0 \cdot 2) a^{\star \star \star \star}, b^{\star \star \star} \\
6(N S) \\
39(0 \cdot 1) a^{\star}, b^{\star \star \star}\end{array}$ & $\begin{array}{l}122(2) \\
35(0 \cdot 4) \\
31(1 \cdot 4) \\
15(1) \\
5(0 \cdot 4) \\
36(1 \cdot 2)\end{array}$ & $\begin{array}{l}125(2) \\
36(0 \cdot 1) \\
31(1 \cdot 6) \\
20(1) c^{\star \star \star} \\
5(0 \cdot 2) \\
31(1) c^{\star}\end{array}$ & $\begin{array}{l}(\mathrm{f}=43, \mathrm{df}=2, \mathrm{p}<0.001) \\
(\mathrm{f}=6, \mathrm{df}=2, \mathrm{p}<0.006) \\
(\mathrm{f}=5, \mathrm{df}=2, \mathrm{p}<0.01) \\
(\mathrm{f}=32, \mathrm{df}=2, \mathrm{p}<0.0001) \\
(\mathrm{f}=2.9, \mathrm{df}=2, \mathrm{p}<0.06) \\
(\mathrm{f}=11, \mathrm{df}=2, \mathrm{p}<0.0002)\end{array}$ \\
\hline $\begin{array}{l}\text { Wechsler Adult Intelligence Scale-F } \\
\text { Full scale IQ } \\
\text { Verbal IQ } \\
\text { Performance IQ } \\
\text { Information } \\
\text { Arithmetic }\end{array}$ & $\begin{array}{l}132(3) a^{\star \star \star \star}, b^{\star \star \star \star} \\
128(3) a^{\star \star \star \star} \\
128(3) a^{\star \star \star \star}, b^{\star \star \star \star} \\
15(0 \cdot 4) b^{\star \star \star \star} \cdot b^{\star \star \star} \\
14(0 \cdot 7) a^{\star \star \star \star}, b^{\star \star \star} \\
b^{\star \star \star \star}\end{array}$ & $\begin{array}{l}89(2) \\
97(3) \\
81(2) \\
9(1) \\
7(0.5)\end{array}$ & $\begin{array}{l}93(5) \\
98(2) \\
78(3) \\
12(1) c^{\star} \\
9(0 \cdot 8) c^{\star}\end{array}$ & $\begin{array}{l}(\mathrm{f}=47, \mathrm{df}=2, \mathrm{p}<0.0001) \\
(\mathrm{f}=39, \mathrm{df}=2, \mathrm{p}<0.0001) \\
(\mathrm{f}=87, \mathrm{df}=2, \mathrm{p}<0.0001) \\
(\mathrm{f}=16, \mathrm{df}=2, \mathrm{p}<0.0001) \\
(\mathrm{f}=31, \mathrm{df}=2, \mathrm{p}<0.0001)\end{array}$ \\
\hline $\begin{array}{l}\text { Wechsler Memory Scale } \\
\text { Memory Quotient } \\
\text { Information } \\
\text { Orientation } \\
\text { Stories } \\
\text { Paired-Associates Total }\end{array}$ & $\begin{array}{l}137(3) a^{\star \star \star \star}, b^{\star \star \star \star} \\
6(0 \cdot 2) a^{\star \star \star \star} \\
4 \cdot 9(0 \cdot 1) a^{\star \star \star \star} \\
11(0 \cdot 8) a^{\star \star \star \star} \\
16(0 \cdot 9) a^{\star \star \star \star \star} a^{\star \star \star \star}, b^{\star \star \star}\end{array}$ & $\begin{array}{l}76(3) \\
3(0 \cdot 4) \\
2 \cdot 6(0 \cdot 5) \\
2(0 \cdot 3) \\
7(0 \cdot 7)\end{array}$ & $\begin{array}{l}94(6) c^{\star} \\
6(0 \cdot 1) c^{\star \star \star \star} \\
4 \cdot 4(0 \cdot 2) c^{\star \star \star} \\
5(0 \cdot 8) c^{\star \star} \\
10(1 \cdot 3)\end{array}$ & $\begin{array}{l}(\mathrm{f}=54, \mathrm{df}=2, \mathrm{p}<0.0001) \\
(\mathrm{f}=25.7, \mathrm{df}=2, \mathrm{p}<0.0001) \\
(\mathrm{f}=11 \cdot 8, \mathrm{df}=2, \mathrm{p}<0.0002) \\
(\mathrm{f}=41.6, \mathrm{df}=2, \mathrm{p}<0.0001) \\
(\mathrm{f}=20, \mathrm{df}=2, \mathrm{p}<0.02)\end{array}$ \\
\hline $\begin{array}{l}\text { Wisconsin Card Sorting Test } \\
\text { Categories } \\
\text { Perseveration } \\
\text { Fail to maintain set } \\
\text { FAS Fluency Test } \\
\text { Supermarket Fluency Test } \\
\text { Hamilton Depression Inventory } \\
\text { Beck Depression Inventory }\end{array}$ & $\begin{array}{l}3 \cdot 5(0 \cdot 5) a^{\star}, b^{\star \star} \\
12(2) a^{\star}, b^{\star} \\
0 \cdot 1(0 \cdot 4)(N S) \\
46(3) a^{\star \star}, b^{\star \star \star} \\
27(2) a^{\star \star \star \star}, b^{\star \star \star \star} \\
2(1) b^{\star \star} \\
6(1)(N S)\end{array}$ & $\begin{array}{l}2(0 \cdot 5) \\
22(3) \\
0 \cdot 7(0 \cdot 7) \\
32(4) \\
15(1) \\
5(1) \\
4(1)\end{array}$ & $\begin{array}{l}1 \cdot 1(0 \cdot 5) \\
26(4) \\
0 \cdot 8(1 \cdot 6) \\
27(3) \\
16(2) \\
10(2) \\
10(3)\end{array}$ & $\begin{array}{l}(\mathrm{f}=7 \cdot 8, \mathrm{df}=2, \mathrm{p}<0.01) \\
(\mathrm{f}=4, \mathrm{df}=2, \mathrm{p}<0.01) \\
(\mathrm{f}=1 \cdot 3, \mathrm{df}=2, \mathrm{p}<0 \cdot 2) \\
(\mathrm{f}=8 \cdot 6, \mathrm{df}=2, \mathrm{p}<0.0001) \\
(\mathrm{f}=22 \cdot 8, \mathrm{df}=2, \mathrm{p}<0.0001) \\
(\mathrm{f}=5 \cdot 8, \mathrm{df}=2, \mathrm{p}<0.001) \\
(\mathrm{f}=3, \mathrm{df}=2, \mathrm{p}<0.056)\end{array}$ \\
\hline
\end{tabular}

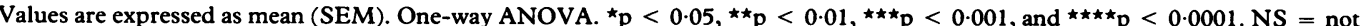
significant; a: controls versus AD patients, $b$ : controls versus $P D$ patients and c: AD versus PD patients. WAIS-R values are agescaled corrected.

There were no significant differences between the three groups in age and education. 
Learning Test (RAVLT) (trials 1-5) were comparable in both patient groups (fig). AD patients forgot significantly more words than PD patients on trial 6 (administered after a 30 minute delay) relative to trial 5 using a measure which represented forgetting rate (total words recalled on trial 5 minus total words recalled on trial 6). Even though PD patients benefited slightly more than $A D$ patients from recognition memory testing (delayed multiple choice testing, one of four words) of the RAVLT words, there was no significant difference between the groups. Both groups of patients had poorer recall of WMS stories and orientation than did control subjects, but patients with AD were significantly more affected that PD patients (table). Recall of WMS paired-associate items were diminished for both groups compared with controls, but failed to differentiate between the $\mathrm{AD}$ and $\mathrm{PD}$ patients (table).

Semantic memory, was differentially compromised in both patient groups in only two measures. Both the information subtest of the WAIS-R and the information subtest of the WMS (two unrelated scales) revealed that Alzheimer's patients were more impaired than PD patients. AD patients were significantly more affected than controls on the information subtest of the WMS, but controls were different from both patient groups on the information subtest of the WAIS-R (table). $A D$ and $P D$ patients performed significantly worse than control subjects in naming, in the FAS Fluency Test, in the Supermarket Fluency Test, and in the vocabulary and

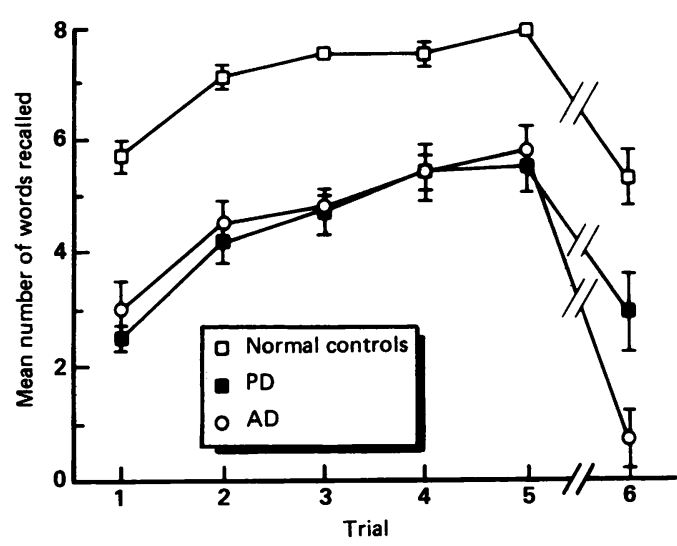

Figure Comparative performance on the modified ReyAuditory Verbal Learning Test. There was a significant difference between the $P D$ and $A D$ patients and the controls on each of the trials (1-5) (repeated measures $A N O V A$, main effects for groups $A D, P D$ and controls: $f: 23 \cdot 7, d f: 2, p<0.0001$; effects for trials $1-5: f: 48 \cdot 7$, df: $4, p<0.001)$. However, there was no difference in learning curve slopes (no significant group per trial interaction). Performance on trial 6 ( 30 minute delay after trial 5) was significantly impaired for both groups in comparison with controls $(p<0.01)$ and for $A D$ in comparison with $P D$ patients $(p<0.02)$ [Mean (SEM), AD: 0.7 (0.5), PD: $2.9(0.7)$, controls: 5.3 ( 0.5 ) one-way ANOVA, $f: 15, d f: 2, p<0.00017$. Forgetting (difference in recall between trials 5 and 6 ) was significantly impaired for $A D$ patients compared with $P D$ patients and controls $(p<0.01$ ) $[A D: 5$

(0.5), PD: $2.6(0.6)$, and controls: $2.5(0.5), f: 5.8, d f$ : $2, p<0.007 /$. Recognition testing did not differentiate between patient groups $(A D: 4 \cdot 6(0.7), P D: 5 \cdot 9(0.6)$ controls: $7.9(0 \cdot 1) 1$, although patients recalled significantly less words than controls. similarities subtests of the WAIS-R. Correlational analysis revealed a consistent relationship for both patient groups between dementia severity (Total Mattis Dementia Rating Scale) and a measure of semantic memory (Supermarket Fluency Test $r=0.67$ for PD and $\mathrm{r}=0.66$ for $\mathrm{AD}$ patients, respectively, $\mathrm{p}<$ 0.05). Only Parkinsonian patients showed a significant association between duration of symptoms and additional semantic memory tasks (that is, FAS Fluency Test, $\mathrm{r}=-0.73$, WAIS-R vocabulary subtest, $\mathrm{r}=-0.66, \mathrm{p}<$ 0.05).

Executive function abnormalities differed between the $P D$ and $A D$ patients. Performance on the conceptualisation subtest of the MDRS was significantly more dysfunctional in PD than in $\mathrm{AD}$ patients although controls performed better than both patient groups (table). Both patient groups performed significantly worse than controls on the WCST as measured by the number of categories and perseveration. Although no significant differences were found between patient groups on any of the measures of the WCST (table), it appeared that some PD patients had particular trouble achieving even one category on the WCST. A Chi-square analysis was computed which compared the percentage of $\mathrm{PD}$ and $\mathrm{AD}$ patients who achieved one or more categories versus those who were unable to achieve even one category. The results of the analysis indicated that $45 \%$ of PD patients compared with $9 \%$ of $\mathrm{AD}$ patients and $0 \%$ of the controls were unable to achieve a single category ( $p<0.01)$. PD patient performance on the MDRS conceptualisation subscale, but not WCST, was strongly correlated with immediate story recall $(\mathbf{r}=$ $0.79, \mathrm{p}<0.01$ ).

Mood as assessed by the Hamilton Depression Scale was no different between PD and AD patients, although PD patients tended to have higher scores, which were slighly above the normal range. PD patients were significantly more depressed than controls (table).

\section{Discussion}

Even though PD and AD patients were matched for global cognitive impairment, there were differences in their specific pattern of intellectual deficits. Some aspects of memory were relatively less affected in PD than in AD patients, while the reverse was seen on executive functions. These results support a previous observation ${ }^{15}$ that performance on memory and executive function tests distinguish demented Parkinsonian from Alzheimer's patients. The above described "functional dissociation" favours the presence of relative neuropathological distinctions between the two diseases. ${ }^{10}$

The two patient groups differed on recall of the Wechsler Memory Scale (WMS) stories and on the 30 minute delayed recall of eight unrelated words as well as on orientation, but were similarly affected on the remaining measures of episodic memory. The results suggest that $P D$ patients are similarly impaired to $\mathrm{AD}$ patients when learning words without 
any inherent organisation (as in the Rey Auditory Learning Test) or learning difficult associations (as in the Pair Associates of the WMS). When PD patients have to retrieve information with a structure, such as the WMS stories, however, they are less impaired than AD patients. This would imply that PD patients may be more able to utilise contextual information and organisation in encoding and recall than patients with $A D$. PD patients perform better on delayed recall on the RAVLT indicating a less steep forgetting curve. Delayed recognition memory was similarly impaired in both patient groups, not withstanding previous reports of spared recognition memory in non-demented PD patients. ${ }^{14162441}$ Recognition memory may be relatively preserved in the early stages of $\mathrm{AD}{ }^{42}$ If we had studied patients in more advanced stages, $\mathrm{AD}$ patients may well have performed worse on recognition memory testing that $\mathrm{PD}$ patients.

Surprisingly, measures that assessed semantic memory generally failed to reveal differences between $\mathrm{PD}$ and $\mathrm{AD}$ patients. These results suggest that previous findings may have been an artifact of the failure to match patient groups for severity of dementia. ${ }^{20-25}$ Semantic memory performance in PD was associated with the duration but not the severity of motor symptoms. In both groups of patients, semantic memory performance was related to the degree of overall dementia. In contrast to the comparison of their memory performance, patients with PD were significantly more impaired than AD patients on a task evaluating conceptual relationships. Although there was no difference between the patient groups on most of the variables studied from the Wisconsin Card Sorting Test (WCST), PD patients tended to perform worse than $\mathrm{AD}$, and had significantly more difficulty in achieving even one category of the WCST. The PD patients' performance on the conceptual relationship task was highly correlated with their performance on an episodic memory measure (story recall) which supports the hypothesis that PD patients encounter difficulties on episodic memory tasks at least partially because of their compromised ability to access organised (that is, conceptual) verbal encoding strategies. ${ }^{14} \mathrm{PD}$ and $\mathrm{AD}$ patients may thus fail on episodic memory tasks for different reasons. In patients with PD, deficits on episodic memory tasks may be due to difficulty in identifying conceptual relations between items. ${ }^{1420}$ This difficulty could partially reflect slowed information processing ${ }^{43}$ which would limit the time and scope of effortful conceptual encoding and retrieval. In addition, depression may also reduce cognitive effort; ${ }^{44}$ although PD patients were more depressed than controls, depression was not associated with cognitive performance in our patient population. Patients with $\mathrm{AD}$ may fail to access items from episodic memory because of problems in contextual encoding and retrieval. Such deficits noted in $A D$ patients are usually linked to their hippocampal lesions, while frontal lobe dysfunction could be responsible for the conceptual impairments in patients with PD. ${ }^{14} 45$

Abnormalities in effortful semantic memory performance observed in PD patients may also be explained by the limited use of conceptual strategies due to frontal lobe dysfunction. ${ }^{25}$ In AD patients, semantic memory deficits may be attributed to a degradation in the knowledge representation systems where items are permanently stored. ${ }^{17}$ This degradation would be dependent on the severity of posterior cortical lesíons.

Qualitative differences in the dementia profiles associated with $\mathrm{AD}$ and PD found in this and previous studies, ${ }^{9} 101446$ support the contention that distinct pathogenetic mechanisms are involved. Nevertheless, in view of the considerable neuropathological and neurochemical overlap between $\mathrm{AD}$ and PD when dementia is present, ${ }^{47-52}$ these differences may well be more relative than absolute.

We thank Dr Jordan Grafman for his valuable suggestions and Ms B J Hessie for editorial assistance.

1 Brown RG, Marsden CD. How common is dementia in Parkinson's disease? Lancet 1984;i:1262-5.

2 Brown RG, Marsden CD. Neuropsychology and cognitive function in Parkinson's disease: an overview. In: Marsden $\mathrm{CD}$, Fahn S, eds. Movement disorders 2. London: ButterCD, Fahn S, eds. Mov
worths, 1987:99-123.

3 Pirozzolo FJ, Hansch EC, Mortimer JA, et al. Dementia in Parkinson disease: A neuropsychological analysis. Brain Cogn 1982;1:71-83.

4 Mortimer JA, Jun SP, Kuskowski MA, Webster DD. Subtypes of Parkinson's disease defined by intellectual impairment. J Neural Transm (Suppl) 1987;24:101-4.

5 Gotham AM, Brown RG, Marsden CD. "Frontal" cognitive function in patients with Parkinson's disease "on" and "off" levodopa. Brain 1988;111:299-321.

6 Taylor AE, Saint-Cyr JA, Lang AE. Parkinson's disease. Cognitive changes in relation to treatment response. Brain 1987;110:35-51.

7 Cummings JL. Subcortical dementia. Neuropsychology, neuropsychiatry, and pathophysiology. Br J Psychiatry 1986;149:682-97.

8 Como PG, Caine ED. A comparative neuropsychological study of $\mathrm{AD}$ and PD. J Clin Exp Neuropsychol 1987;9:74.

9 Stern Y, Sano M, Mayeux R. Comparisons of dementia and intellectual change in Parkinson's and probable Alzheimer's disease. J Clin Exp Neuropsychol 1987;9:66.

10 Brown RG, Marsden CD. "Subcortical dementia". The neuropsychological evidence. Neuroscience 1988;25: 363-87.

11 Boller F, Mizutani T, Roessmann U, Gambetti P. Parkinson disease, dementia, and Alzheimer disease clinicopathological correlations. Ann Neurol 1980;7:329-35.

12 Hakim AM, Mathieson G. Dementia in Parkinson disease: A neuropathologic study. Neurol 1979;29:1209-14.

13 Mayeux R, Stern Y, Rosen J, Benson DF. Is "subcortical dementia" a recognizable clinical entity? Ann Neurol 1983;12:278-83.

14 Taylor AE, Saint-Cyr JA, Lang AE. Frontal lobe dysfunction in Parkinson's disease. The cortical focus of neostriatal outflow. Brain 1986;109:845-83.

15 Pillon B, Dubois B, Lhermitte F, Agid Y. Heterogeneity of conitive impairment in progressive supranuclear palsy, Parkinson's disease and Alzheimer's disease. Neurol 1986;36:1179-85.

16 Lees AJ, Smith E. Cognitive deficits in the early stages of Parkinson's disease. Brain 1983;106:257-70.

17 Weingartner H, Grafman J, Boutelle W, Kaye W, Martin P. Forms of memory failure. Science 1983;21:380-2.

18 Butters N, Granholm E, Salmon DP, Grant I. Episodic and semantic memory: a comparison of amnesic and demented pemantic memory: a comparison of amnesic and de

19 Tulving E. Episodic and semantic memory. In: Tulving E, Donaldson W, eds. Organization of Memory. New York and London: Academic Press, 1972:382-403.

20 Weingartner H, Burns S, Diebel R, LeWitt PA. Cognitive impairments in Parkinson's disease: Distinguishing between effort-demanding and automatic cognitive processes. Psychol Res 1984;11:223-35.

21 Talland GA. Cognitive function in Parkinson's disease. $J$ Nerv Ment Dis 1962;135:196-205.

22 Bowen FP, Burn MM, Yahr MD. Alterations in memory processes subsequent to short and long term treatment with L-dopa. In: Birkmeyer $W$, Hornykiewicz $O$, eds. Advances in Parkinsonism. Geneva: Roche, 1976:488-91.

23 Mortimer IA, Pirozzolo FJ, Hansch EC, Webster DD. ortimer JA, Pirozzolo FJ, Hansch EC, Webster DD. Parkinson disease. Neurology 1982;32:133-7. 
24 Tweedy JR, Langer KG, McDowell FH. The effect of semantic relations on the memory deficit associated with semantic relations on the memory deficit associated with

25 Matison R, Mayeux R, Rosen J, Fahn S. "Tip-of-thetongue" phenomenon in Parkinson's disease. Neurology 1982;32:567-70.

26 Mattis S. Mental status examination for organic mental syndrome in the elderly. In: Bellack L, Karasu TB, eds. Geriatric Psychiatry. New York: Grune and Stratton, 1976:77-121.

27 American Psychiatric Association. Diagnostic and statistical manual of mental disorders. Washington DC: American Psychiatric Association, 1987: third ed (revised).

28 McKhann G, Drachman D, Folstein M, Katzman R, Price D, Stadlan EM. Clinical diagnosis of Alzheimer's disease: A report of the NINCDS-ADRDA work group under the auspices of the Department of Health and Human Services auspices of the Department of Health and Human Services
Task Force on Alzheimer's disease. Neurology Task Force on

29 Montgomery GK, Reynolds NC, Warren RM. Qualitative assessment of Parkinson's disease: study of reliability and data reduction with an abbreviated Columbia scale. Clin Neuropharmacol 1985;8:83-92.

30 Mohr E, Litvan I, Williams J, Fedio P, Chase TN. Selective deficits in Alzheimer and Parkinsonian dementia: Visuoatial function. (In press).

31 Wechsler D, Stone C. Wechsler Memory Scale. New York: Psychological Corporation, 1955.

32 Rey A. L'examen clinique en psychologie. Paris: Presses Universitaires de France, 1964.

33 Benton AL. Differential behavioral effects in frontal lobe disease. Neuropsychologia. 1968;6:53-60.

34 Wechsler D. WAIS-R Manual. New York: Psychological Corporation, 1981 .

35 Kaplan E, Goodglass H, Weintraub S. Boston Naming Test (experimental edition). Boston: Boston Veterans Administration Medical Center, 1976.

36 Heaton RK. Wisconsin Card Sorting Test Manual. Odessa, Florida: Psychological Assessment Resources, 1981

37 Hamilton H. A rating scale for depression. J Neurol Neurosurg Psychiatry 1960;23:56-62.

38 Beck AT, Ward CH, Mendelson M, Mock J, Erbaugh J. An inventory for measuring depression. Arch Gen Psychiatry 1961;4:561-71.
39 Brown M, Engelman L, Frane JW, Hill MA, Jennrich RI, Toporek JD. BMDP Statistical Software. Los Angeles: Toporek JD. BMDP Statistical Softwar

40 Joyner SP. SAS User's guide: statistics, fifth ed. Cary, NC: SAS Institute 1985:827-9.

41 Flowers KA, Pearce I, Pearce JMS. Recognition memory in Parkinson's disease. J Neurol Neurosurg Psychiatry 1984;47:1174-81.

42 Vitaliano PP, Breen AR, Albert MS, Russo J, Prinz PN. Memory, attention, and functional status in communityresiding Alzheimer type dementia patients and optimally healthy aged individuals. J Gerontol 1984;39:58-64.

43 Mayeux R, Stern Y, Sano M, et al. Clinical and biochemical correlates of bradyphrenia in Parkinson's disease. correlates of bradyphren
Neurology $1987 ; 37: 1130-4$.

44 Speedie LJ, Shemesh Z, Gilon D, Raphael M, Stessman J, Wertman EJ. Cognitive changes in Parkinsonian patients with depression. J Clin Exper Neuropsychol 1989;11:96.

45 Caltagirone C, Masullo C, Benedetti N, Nocentini U. Profilo di compromissione neuropsicologica in pazienti affetti da morbo di Parkinson. Archivo Svizzero di Neurologia, Neurochirurgia e Psichiatria 1985;136:7-23.

46 Sagar HJ, Cohen NJ, Sullivan EV, et al. Remote memory function in Alzheimer's disease and Parkinson's disease. Brain 1988;11:185-206.

47 Gaspar P, Gray F. Dementia in idiopathic Parkinson's disease. A neuropathological study of 32 cases. Acta Neuropathol (Berl) 1984;64:43-52.

48 Yoshimura $M$. Cortical changes in the parkinsonian brain: $A$ contribution to the delineation of "diffuse Lewy body contribution to the delineation of "d
disease." $J$ Neurol 1983;229:17-32.

49 Whitehouse PJ, Hedreen JC, White CL, Price DL. Basal forebrain neurons in idiopathic Parkinson's disease. Ann Neurol 1983;13:243-8.

50 Ball MJ. The morphological basis of dementia in Parkinson's disease. Can J Neurol Sci 1984;11:180-4.

51 Dubois B, Hauw JJ, Ruberg M, Serdaru M, Javoy-Agid F, Agid Y. Demence et maladie de Parkinson: Correlations biochemiques et anatomo-cliniques. Rev Neurol (Paris) 1985;141:184-93.

52 Perry EK, Curtis M, Dick DJ, et al. Cholinergic correlates of cognitive impairment in Parkinson's disease: comparison with Alzheimer's disease. J Neurol Neurosurg Psychiatry 1985;48:413-21. 